\title{
Kinetics and characteristics of phenanthrene degradation by a microbial consortium
}

\author{
Wang Jing*, Xu Hongke, An Mingquan and Yan Guiwen \\ School of Chemical Science \& Engineering, China University of Petroleum, Beijing 102249, China
}

\begin{abstract}
The kinetics and characteristics of phenanthrene degradation by a microbial consortium W4 isolated from Henan Oilfield were investigated. The degradation percentage of solid phenanthrene at 200 $\mathrm{mg} / \mathrm{L}$ in liquid medium after 6 days of incubation was higher than $95 \%$ under the condition of $37^{\circ} \mathrm{C}$ and $120 \mathrm{r} / \mathrm{min}$ by this microbial consortium. The degradation of phenanthrene could be fitted to a first-order kinetic model with the half-life of 1.25 days. The optimum conditions for degradation of phenanthrene by consortium W4 were as follows: temperature about $37^{\circ} \mathrm{C}$, pH from 6.0 to 7.0 and salinity about $8.0 \mathrm{~g} / \mathrm{L}$. It was concluded that microbial consortium W4 might degrade phenanthrene via both salicylic acid and o-phthalic acid pathways by analyzing products with GC-MS.
\end{abstract}

Key words: Phenanthrene, biodegradation, kinetics, microbial consortium

\section{Introduction}

Polycyclic aromatic hydrocarbons (PAHs) are common soil pollutants at gas works sites, oil refineries and wood treatment facilities. PAHs are highly toxic and several kinds of PAHs, including phenanthrene, fluorene and fluoranthene, are listed by the US Environmental Protection Agency (USEPA) as priority pollutants and are potential carcinogens (Viamajala et al, 2007; Eriksson et al, 2003; van Herwijnen et al, 2003) and mutagens (Xia et al, 2006). However, due to low aqueous solubility, tendency to adhere strongly to sediment particles and low concentrations of particular electron acceptors (Tang and Krieger-Brockett, 2007), PAHs accumulate in solid phases (Leglize et al, 2006) and deposit in the soil environment (Shin et al, 2006). PAHs exist in the environment for years owing to their nonpolarity, hydrophobicity and adsorption to solid particles. Guo et al (2007) investigated the distribution of polycyclic aromatic hydrocarbons (PAHs) in sediment samples from the Songhuajiang River (Northeast China) in flood season (i.e. August, 2005) and icebound season (i.e. December, 2005). The results showed that in flood season, the total PAHs concentrations in sediments ranged from 84.44 to $14,938.73$ $\mathrm{ng} / \mathrm{g}$, with an average of $2,430.37 \mathrm{ng} / \mathrm{g}$, and in icebound season, the total PAHs concentrations in sediments ranged from 23.61 to $15,310.25 \mathrm{ng} / \mathrm{g}$, with an average of $1,825.60 \mathrm{ng} /$ g. The level of PAHs was higher than that reported from other river and marine systems in the world. PAHs contamination could be remedied by chemical, physical or biological methods. Chemical methods can lead to formation of toxic compounds (Viamajala et al, 2007). PAHs do not degrate by physical methods at ambiemt temperatures. Chemical or physical methods might lead to secondary contamination. Bioremediation is regarded as the best method to detoxify

*Corresponding author. e-mail: swhgwj898@cup.edu.cn

Received January 19, 2007
PAHs (Tao et al, 2007), and biodegradation is the key process for removal of PAHs from the environment (Xia et al, 2006). According to Alexander (1999), the bioremediation efficiency is related to the activity of inoculated microbial degraders in natural environment. Thus, bioaugmentation of contaminations should be preceded by a series of laboratory evaluations, particularly by characterization of the microbial populations, including degradation kinetics, aiming to evaluate the capacity of selected microorganisms to colonize and to remediate PAHs-contaminated environment. Tang et al (2007) measured the mineralization rates of ${ }^{14} \mathrm{C}$-phenanthrene in contaminated, undisturbed marine sediments by using the whole core injection method to assess the natural attenuation of microbial activity as a function of sediment depth. Experiments showed significant biodegradation activities (0.0012-0.0036 day $\left.{ }^{-1}\right)$ in the sediment depth from 0 to 10 $\mathrm{cm}$ (Tang et al, 2007). A mathematical simulation described the diffusion and simultaneous biodegradation (Monod kinetics) of the competing contaminant ${ }^{14} \mathrm{C}$-phenanthrene, and developed the first-order kinetics of the apparent ${ }^{14} \mathrm{C}$-phenanthrene biodegradation approach.

Effective microbial consortium has attracted the attention of researchers worldwide due to the synergistic interactions among members of the consortium. Phenanthrene was often used as a model substance for microbial metabolism of "bayregion" and "K-region" containing carcinogenic PAHs (Tao et al, 2007).

A microbial consortium W4 from Henan Oilfield was enriched in our laboratory. This could effectively degrade phenanthrene (Rodrigo et al, 2007). The present study investigated the kinetics, mechanism, and the influence of temperature, $\mathrm{pH}$ and salinity on biodegradation of phenanthrene by the microbial consortium W4. It could be helpful in improving the efficiency of degradation of phenanthrene and other PAHs, and to remediate PAHscontaminated environment. 


\section{Materials and methods}

\subsection{Materials}

Phenanthrene was purchased from Beijing Chemicals, China, purity $27.0 \%$. All other reagents were analytical-reagent grade.

\subsection{Microbial consortium and culture medium}

Microbial consortium W4 was isolated from Henan Oilfield, and it consisted of 4 bacterial strains: Sphingomonas cloacae W4-1, Rhizobium sp. strain W4-2, Pseudomonas aeruginosa W4-3 and Achromobacter xylosoxidants W4-4 (Wang et al, 2007). Mineral salt medium (MSM) was used as the culture medium and it had the following composition in distilled water $(\mathrm{g} / \mathrm{L}): \mathrm{K}_{2} \mathrm{HPO}_{4} \cdot 3 \mathrm{H}_{2} \mathrm{O}, 3 ; \mathrm{KH}_{2} \mathrm{PO}_{4}, 3 ; \mathrm{NaCl}, 0.5$; $\mathrm{NH}_{4} \mathrm{Cl}, 1 ; \mathrm{MgSO}_{4} \cdot 7 \mathrm{H}_{2} \mathrm{O}, 0.5 ; \mathrm{CaCl}_{2}$ (trace); $\mathrm{FeCl}_{3}$ (trace). The medium $\mathrm{pH}$ was around 6.6. Phenanthrene was added directly into MSM in solid state (Li et al, 2004).

\subsection{Biodegradation of phenanthrene}

To prepare the microbial consortium, loopfuls of each isolated species on nutrient agar plate were inoculated together into $50 \mathrm{~mL}$ MSM containing $200 \mathrm{mg} / \mathrm{L}$ phenanthrene in conical flask. The flask was shaken in an orbital shaker (120 $\mathrm{r} / \mathrm{min}$ ) at $37{ }^{\circ} \mathrm{C}$ in the dark for 4 days to reach the exponential growth phase. To start the biodegradation experiment, $2 \mathrm{~mL}$ aliquot of the culture was added aseptically to $50 \mathrm{~mL}$ MSM containing $200 \mathrm{mg} / \mathrm{L}$ Phe to give an initial $\mathrm{OD}_{600}$ of around 0.01-0.015. The flasks were shaken in the same way as mentioned above. Control flasks with MSM containing 200 $\mathrm{mg} / \mathrm{L}$ phenanthrene (but no bacterial consortium) was also prepared and cultured for 6 days to check for abiotic loss of phenanthrene during study. Seven groups with different culture times (1, 2, 3, 4, 5, 6 and 14 days, respectively) were set with triplicates for each group. The residual phenanthrene and major metabolites in the cultures of each group were analyzed by GC-MS.

\subsection{Biodegradation rate and major metabolites}

To extract phenanthrene and its major metabolites, 50 $\mathrm{mL}$ of cell suspension was harvested and acidified to $\mathrm{pH}$ 2.0 with $1 \mathrm{M} \mathrm{HCl}$. The system was first extracted with 25 $\mathrm{mL}$ of dichloromethane twice and then extracted with 25 $\mathrm{mL}$ of ethyl acetate for twice. The dichloromethane solvent was evaporated in a water bath at $42{ }^{\circ} \mathrm{C}$ and the solution was concentrated to a specific volume (Table 1). The ethyl acetate solvent was evaporated in a water bath at $82{ }^{\circ} \mathrm{C}$ and the solution was then concentrated to $0.5 \mathrm{~mL}$. Finally $0.5 \mathrm{~mL}$ dichloromethane solution and $0.5 \mathrm{~mL}$ ethyl acetate solution were mixed together for GC-MS analysis (Xu et al, 2004; Samamta et al, 1999; Kim et al, 2005). The control flask was extracted with $25 \mathrm{~mL}$ of dichloromethane twice and then fixed to $50 \mathrm{~mL}$, and $1 \mathrm{~mL}$ of which was taken for GC-MS analysis. A series of solutions with different concentrations were used to make the external standard curve. All the samples for GCMS were sent to the Analytical Service Center of State Key Laboratory of Heavy Oil Processing, China University of Petroleum (Beijing). The GC-MS analysis was performed by Thermo-Finngan Trace DSQ. Gas Chromatography was equipped with a quartz capillary $(30 \mathrm{~m} \times 0.25 \mathrm{~mm} \times 0.25 \mu \mathrm{m})$. Helium was used as carrier gas (16spi). The injector temperature was $300{ }^{\circ} \mathrm{C}$. The initial oven temperature was 80 ${ }^{\circ} \mathrm{C}$ (with a holding time of $1 \mathrm{~min}$ ) and then increased to 300 ${ }^{\circ} \mathrm{C}$ at $8{ }^{\circ} \mathrm{C} / \mathrm{min}$, with a final holding time of $5 \mathrm{~min}$; injection was performed in split mode $(60: 1)$ at a constant temperature. Mass spectrometry operating conditions were as follows: scan time of $0.8 \mathrm{~s}$ and a mass-range of 35-400 amu; EI (electron impact) of $70 \mathrm{eV}$, emission current of $200 \mu \mathrm{A}$.

Table 1 Concentrated volume of different samples

\begin{tabular}{cccccccc}
\hline Reaction time, days & 1 & 2 & 3 & 4 & 5 & 6 & 14 \\
\hline $\begin{array}{c}\text { Concentrated } \\
\text { volume, } \mathrm{mL}\end{array}$ & 50 & 50 & 25 & 25 & 10 & 5 & 0.5 \\
\hline
\end{tabular}

\subsection{Influence of fermentation temperature, $\mathrm{pH}$ and} salinity on biodegradation of phenanthrene

A L9 $\left(3^{3}\right)$ orthogonal test table was used to investigate the influence of main parameters, namely the biodegradation temperature, $\mathrm{pH}$ and salinity, on phenanthrene biodegradation.

To prepare the microbial consortium, loopfuls of each isolated species on nutrient agar plate were inoculated together into $50 \mathrm{~mL}$ MSM confected from the orthogonal test table containing $200 \mathrm{mg} / \mathrm{L}$ phenanthrene in conical flask. The flask was also shaken in an orbital shaker $(120 \mathrm{r} / \mathrm{min})$ at $37{ }^{\circ} \mathrm{C}$ in the dark for 4 days and the cell suspension was harvested.

To extract the residual phenanthrene, the method above was exactly followed. Finally $1.5 \mathrm{~mL}$ dichloromethane solution was harvested for GC-MS analysis (Xu et al, 2004; Samamta et al, 1999; Kim et al, 2005). Three other solutions with different concentrations were used to make an external standard curve. All the samples for GC-MS were sent to the Analytical Service Center of State Key Laboratory of Heavy Oil Processing, China University of Petroleum (Beijing).

\section{Results and discussion}

\subsection{Identification of phenanthrene metabolites and metabolic pathway}

To explore the metabolic pathways of phenanthrene by microbial consortium W4, major metabolites of phenanthrene in culture medium at different times were identified using GCMS by comparing their mass spectra with the spectra from National Institute of Standards and Technology (NIST) (Table $3)$. Three kinds of metabolites were observed in the first two days, while only one kind in the later days. The reason might be that according to the kinetics of enzyme-catalyzed reactions, the biodegradation rate of initial substrate was greater than that of intermediates by consortium W4 at the beginning, resulting in large accumulation of intermediates. With the decrease of phenanthrene as well as the increase of intermediates, the biodegradation rate of intermediates by consortium $\mathrm{W} 4$ increased and the intermediates were finally degraded into $\mathrm{CO}_{2}$ and $\mathrm{H}_{2} \mathrm{O}$ (data not listed) except some substances with relative low degradability. By analyzing the structure of metabolites, 1-hydroxy-2-naphthoic acid, 
Table 2 Primary variables and the levels used for orthogonal design

\begin{tabular}{cccc}
\hline \multirow{2}{*}{ Levels } & \multicolumn{3}{c}{ Main variables } \\
\cline { 2 - 4 } & Temperature, ${ }^{\circ} \mathrm{C}$ & $\mathrm{pH}$ & Salinity, $\mathrm{g} / \mathrm{L}$ \\
\hline I & 30 & 5.0 & 4.0 \\
II & 37 & 6.5 & 6.0 \\
III & 45 & 8.0 & 8.0 \\
\hline
\end{tabular}

1-naphthol, salicylic acid and catechol were observed in the first two days, showing the salicylic acid pathway. There was no catechol but o-phthalic acid observed after 14 days of degradation, indicating the o-phthalic acid pathway (Wang et al, 2006) and the disappearance of catechol through degradation. As a result, it could be suggested that two pathways were involved in the degradation of phenanthrene by consortium W4 (Fig. 1). In addition, catechol could be degraded much more easily than o-phthalic acid.

\subsection{Biodegradation kinetics of phenanthrene}

Consortium W4 could grow on phenanthrene as the sole carbon source. The concentrations of residual phenanthrene in cultures after different times of W4 cultivation were quantified through GC-MS. The concentration of residual phenanthrene of control sample was $191.72 \mathrm{mg} / \mathrm{L}$ after 6 days, so the abiotic loss (including evaporation loss, extraction loss and measurement error) was about $4.14 \%$. A typical growth curve of consortium W4 in batch cultivation supplied with phenanthrene at $200 \mathrm{mg} / \mathrm{L}$ is shown in Fig. 2.

There was hardly any lag phase observed and the growth reached the steady phase about 5 days later. In addition, the phenanthrene concentration decreased more rapidly in the first two days than in the later days, and this might be attributed to the higher concentration of substrate at the beginning and the inhibited degradation of phenanthrene to some extent by metabolites later. The concentration of residual phenanthrene was $9.28 \mathrm{mg} / \mathrm{L}$ and the degradation percentage of phenanthrene was greater than $95 \%$ after 6 days of W4 incubation. There was positive correlation between the degradation of phenanthrene and the growth of consortium W4 according to Fig. 2.

The plot of the natural logarithm of phenanthrene concentration versus time shown in Fig. 3 is linear $\left(\mathrm{R}^{2}=0.9925\right)$ under the test conditions, fitting to the Monod first-order kinetic equation as follows: $\operatorname{lnC}=-\mathrm{Kt}+\mathrm{A}$, where $\mathrm{C}$ is the phenanthrene concentration, $\mathrm{t}$ represents time, $\mathrm{K}$ is the first-order rate constant and $\mathrm{A}$ is a constant. The half-life of phenanthrene biodegradation by consortium W4 could be calculated according to the equation: $t_{1 / 2}=0.693 / \mathrm{K}$.

The rate constant $\mathrm{K}$ and constant $\mathrm{A}$ obtained from our experiment results were $0.5547 \mathrm{~d}^{-1}$ and 5.6597 , respectively. Therefore, the first-order equation could be expressed as: $\ln C=-0.5547 \mathrm{t}+5.6597$, and the half-life was $1.25 \mathrm{~d}$. As a result, in our experiment, biodegradation of phenanthrene by consortium W4 fitted to first-order reaction kinetics. Other

Table 3 Major Metabolites of phenanthrene at different times

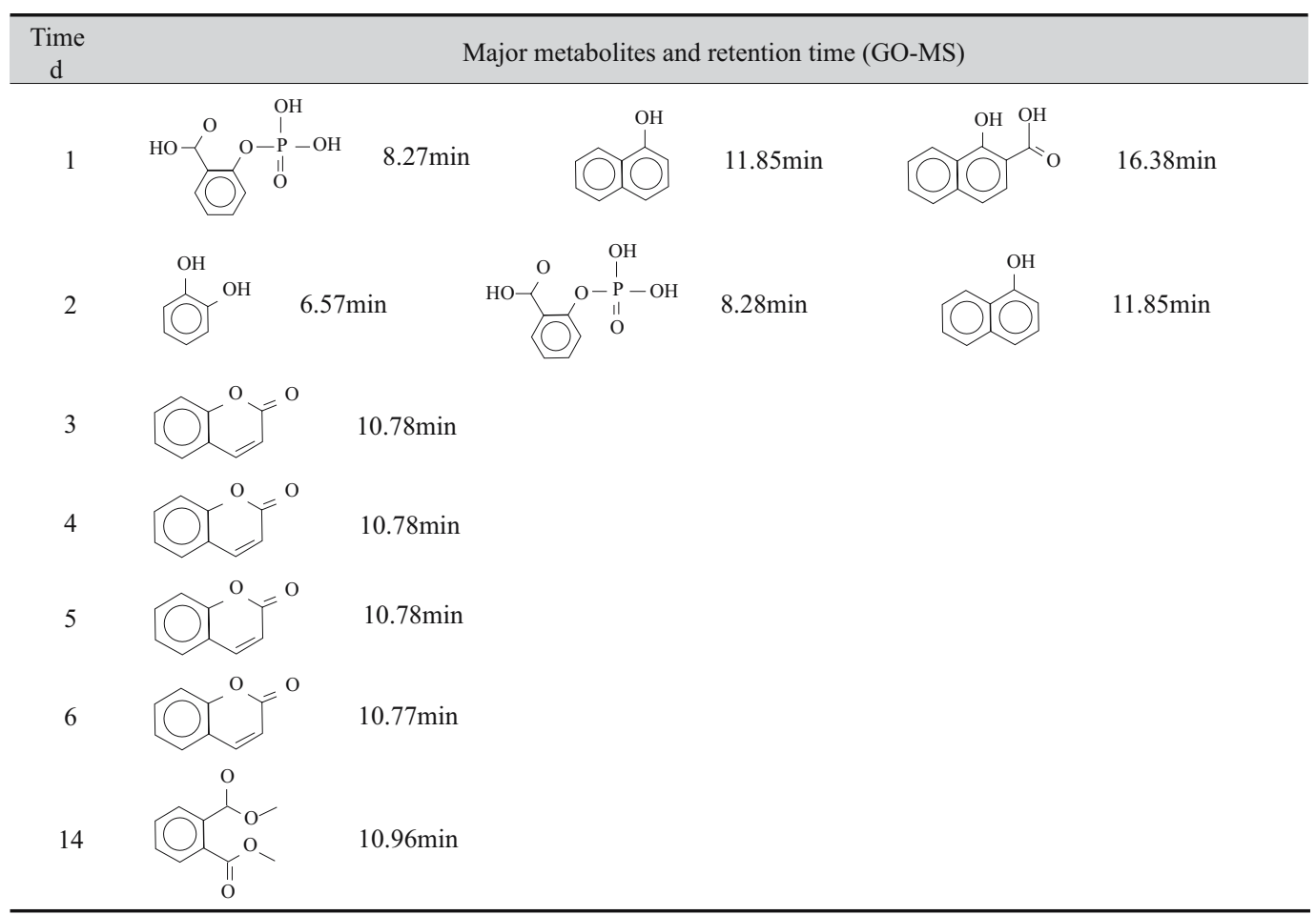




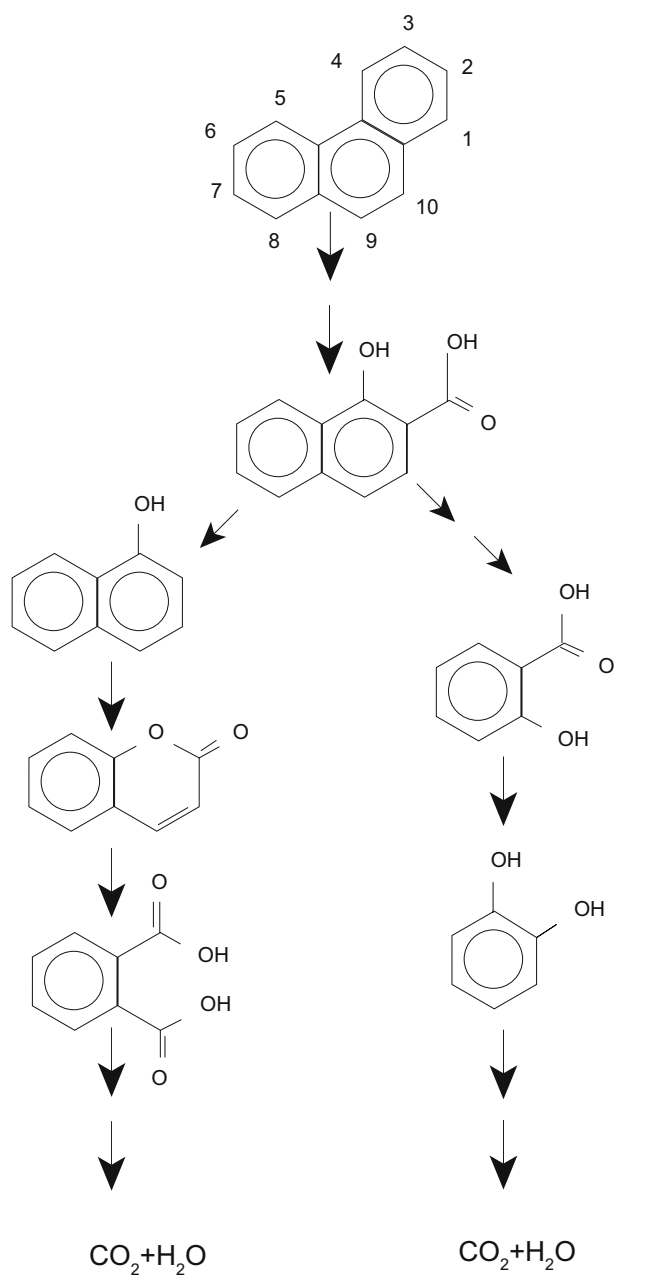

Fig. 1 Putative metabolic pathways of phenanthrene by consortium W4

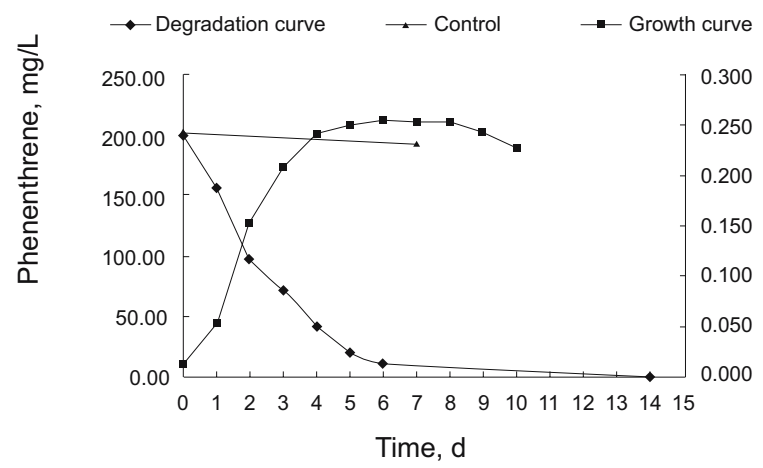

Fig. 2 Degradation of phenanthrene and growth of microbial consortium W4

researchers also reported that biodegradation of certain compound as single substrate fitted to first-order reaction kinetics (Xu et al, 2006; Atuanya and Chakrabarti, 2004).

\subsection{Influences of primary variables on biodegradation of phenanthrene}

An orthogonal design L9 $\left(3^{3}\right)$ was used to optimize the biodegradation temperature, $\mathrm{pH}$ and salinity (Table 4).

The range of factors was used to ascertain the relative importance of temperature, $\mathrm{pH}$ and salinity in orthogonal experiments. Table 5 shows the range analysis of L9 $\left(3^{3}\right)$ orthogonal experiments of the residual phenanthrene concentration. The results showed that the range $(\mathrm{R})$ of factor A, B, C was 58.437, 88.494 and 9.901, respectively. The larger $\mathrm{R}$ value of a factor represents greater effect on the final phenanthrene concentration. According to the range, the order of influence is: $\mathrm{pH}>$ temperature $>$ salinity. The optimal condition for improving degradation efficiency was determined as experiment No.5. Thus the optimal fermentation condition was determined as follows: temperature $37^{\circ} \mathrm{C}$, pH 6.5 and salinity $8.0 \mathrm{~g} / \mathrm{L}$ (Fig.4).

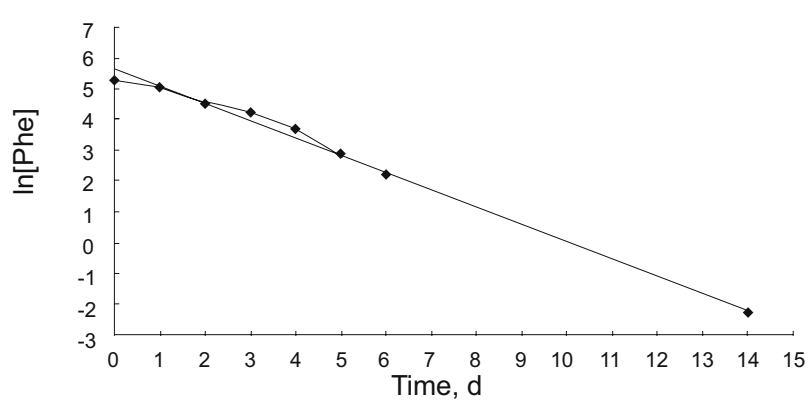

Fig. 3 Plot of the natural logarithm of phenanthrene concentration vs. time for degradation of phenanthrene by microbial consortium W4

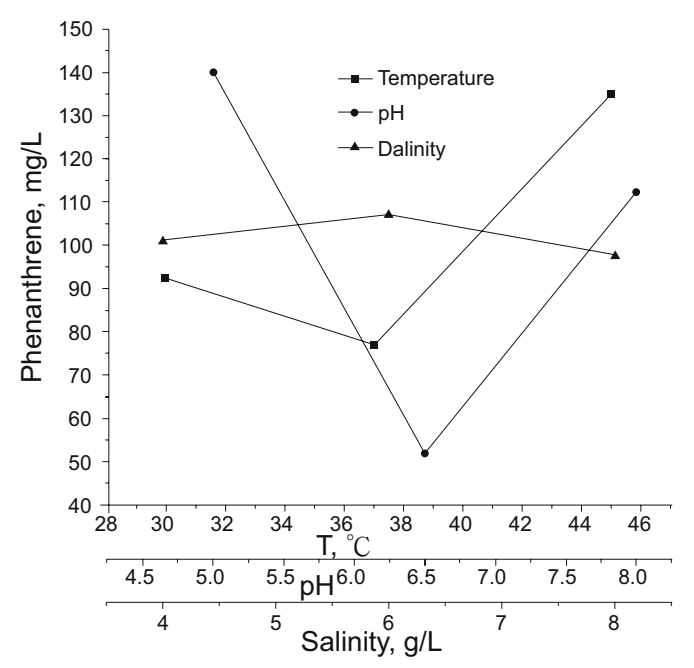

Fig. 4 Final phenanthrene concentration at different levels and factors

\section{Conclusions}

1) The degradation percentage of phenanthrene at 200 $\mathrm{mg} / \mathrm{L}$ after 6 days of incubation was greater than $95 \%$ by consortium W4.

2) The degradation of phenanthrene could be fitted to a first-order kinetic model with the half-life of $1.25 \mathrm{~d}$.

3) The optimum conditions for degradation of phenanthrene by consortium W4 were as follows: temperature about $37^{\circ} \mathrm{C}$, pH from 6.0 to 7.0 and salinity about $8.0 \mathrm{~g} / \mathrm{L}$.

4) It was concluded that microbial consortium W4 might degrade phenanthrene via both salicylic acid and o-phthalic acid pathways at the same time.

In order to achieve more effective degradation of phenanthrene by the consortium, further studies should 
Table 4 Results under experiment conditions using L9 $\left(3^{3}\right)$ orthogonal design

\begin{tabular}{cccccc}
\hline \multirow{2}{*}{ Experiment $\mathrm{No}$} & $\begin{array}{c}\mathrm{T},{ }^{\circ} \mathrm{C} \\
\mathrm{A}\end{array}$ & $\begin{array}{c}\mathrm{pH} \\
\mathrm{B}\end{array}$ & $\begin{array}{c}\text { Salinity } \mathrm{NaCl}, \mathrm{g} / \mathrm{L} \\
\mathrm{C}\end{array}$ & $\begin{array}{c}\text { Phenanthrene, } \mathrm{mg} / \\
\mathrm{L}\end{array}$ & $\begin{array}{c}\text { Degradation } \\
\text { efficiency, } \%\end{array}$ \\
\hline 1 & 30 & 5.0 & 4.0 & 112.218 & 43.891 \\
2 & 30 & 6.5 & 6.0 & 31.197 & 84.401 \\
3 & 30 & 8.0 & 8.0 & 134.532 & 32.734 \\
4 & 37 & 5.0 & 6.0 & 156.274 & 21.863 \\
5 & 37 & 6.5 & 8.0 & 3.822 & 98.089 \\
6 & 37 & 8.0 & 4.0 & 71.015 & 64.492 \\
7 & 45 & 5.0 & 8.0 & 152.615 & 23.692 \\
8 & 45 & 6.5 & 4.0 & 120.604 & 39.698 \\
9 & 45 & 8.0 & 6.0 & 133.202 & 33.397 \\
\hline
\end{tabular}

Table 5 The range analysis of L9 $\left(3^{3}\right)$ orthogonal experiments

\begin{tabular}{ccccc}
\hline & & $\mathrm{T},{ }^{\circ} \mathrm{C}$ & $\mathrm{pH}$ & \multicolumn{2}{c}{ Salinity $\mathrm{NaCl}, \mathrm{g} / \mathrm{L}$} \\
$\mathrm{C}$ & $\mathrm{A}$ & $\mathrm{C}$ & 303.837 \\
\hline \multirow{3}{*}{$\mathrm{K}($ Sum $)$} & $\mathrm{I}^{\mathrm{a}}$ & 277.947 & 421.107 & 320.673 \\
& $\mathrm{II}^{\mathrm{a}}$ & 231.111 & 155.623 & 290.969 \\
& $\mathrm{III}^{\mathrm{a}}$ & 406.421 & 338.749 & 101.279 \\
& $\mathrm{I}^{\mathrm{b}}$ & 92.649 & 140.369 & 106.891 \\
$\mathrm{k}($ Average $)$ & $\mathrm{II}^{\mathrm{b}}$ & 77.037 & 51.875 & 96.990 \\
& $\mathrm{III}^{\mathrm{b}}$ & 135.474 & 112.916 & 9.901 \\
\hline
\end{tabular}

Notes: a. The overall reponse of each level to extraction yield of different fators.

b. Average response of each level to extraction yield.

c. $R$ value means the range between four average responses of each level to the final phenanthrene concentration

be focused on the mechanisms of synergistic interactions among members of the consortium during degradation of phenanthrene, and on various factors influencing degradation pathway and degradation efficiency.

\section{References}

Alexander M. Biodegradation and bioremediation. New York: Academic Press. 1999

Atuanya E I and Chakrabarti T. Kinetics of biotransformation of 2, 4-dichlorophenol using UASB-reactor. Environmental Monitoring and Assessment. 2004. 96: 129-141

Eriksson M, Sodersten E, Yu Z, et al. Degradation of polycyclic aromatic hydrocarbons at low temperature under aerobic and nitratereducing conditions in enrichment cultures from northern soils. Appl. Environ. Microbiol. 2003. 69: 275-284

Guo W, He M C, Yang Z F, et al. Comparison of polycyclic aromatic hydrocarbons in sediments from the Songhuajiang River (China) during different sampling seasons. Journal of Environmental Science and Health, Part A: Toxic/Hazardous Substances \& Environmental Engineering, 2007. 42(2): 119-127

K im Y K, Freeman J P, Moody J D, et al. Effects of $\mathrm{pH}$ on the degradation of phenanthrene and pyrene by Mycobacterium vanbaalenii PYR-1. Appl. Microbiol. Biotechnol. 2005. 67: 275-285
Leglize P, Alain Berthelin J, et al. Evaluation of matrices for the sorption and biodegradation of phenanthrene. WATER RESEARCH. 2006. 40: $2397-2404$

Li X W, Liu Z P and Liu S J. Character of a new bioemulsifier and its influence on biodegradation of polycyclic aromatic hydrocarbons (PAHs). Acta Microbiologica Sinica. 2004. 44(3): 373-377 (in Chinese)

Rodrigo J, Jacques S, Benedict C, et al. Microbial consortium bioaugmentation of a polycyclic aromatic hydrocarbons contaminated soil. Bioresource Technology. 2007 (paper in press)

Samamta S K, Chakraborti A K and Jain R K. Degradation of phenanthrene by different bacteria: evidence for novel transformation sequence involving the formation of 1-naphthol. Appl. Microbiol. Bietechnol. 1999. 53: 98-107

Shin K H, Kim K W and Ahn Y. Use of biosurfactant to remediate phenanthrene-contaminated soil by the combined solubilizationCbiodegradation process. Journal of Hazardous Materials. 2006. B137: 1831-1837

Tang Y J and Krieger-Brockett B. Mathematical analysis of the whole core injection method accuracy for measuring phenanthrene biodegradation rates in undisturbed marine sediments. Chemosphere. 2007. 68: 804-813

Tao X Q, Lu G N, Dang Z, et al. A phenanthrene-degrading strain Sphingomonas sp. GY2B isolated from contaminated soils. Process 
Biochemistry. 2007. 42: 401-408

van Herwijnen R, Wattiau P, Bastiaens L, et al. Elucidation of the metabolic pathway of fluorene and co-metabolic pathways of phenanthrene, fluoranthene, anthracene and dibenzothiphene by Sphingomonas sp. LB126. Res. Microbiol. 2003. 154: 199-206

Viamajala S, Peyton B M, Richards L A, et al. Solubilization, solution equilibria, and biodegradation of PAH's under thermophilic conditions. Chemosphere. 2007. 66: 1094-1106

Wang J, Xu H K, Guo S H, et al. Isolation and characteristics of a microbial consortium for effectively degrading phenanthrene. Petroleum Science. 2007. 4(3): 68-75

Wang J, Xu H K, Liu Y Q, et al. Advances in mechanism of microbial degradation of phenanthrene. Microbiology. 2006. 33(5): 138-144 (in
Chinese)

Xia X H, Yu H, Yang Z F, et al. Biodegradation of polycyclic aromatic hydrocarbons in the natural waters of the Yellow River: Effects of high sediment content on biodegradation. Chemosphere. 2006. 65: 457-466

$\mathrm{Xu} \mathrm{H}$, Zhang J, Liu C L, et al. Isolation and identification of PAHdegrading strains and their degradation capability. Marine Environmental Science. 2004: 23(3), 61-64 (in Chinese)

Xu X R, Li H B, Gu J D, et al. Kinetics of n-butyl benzyl phthalate degradation by a pure bacterial culture from the mangrove sediment. Journal of Hazardous Materials. 2006: 140(1-2), 194-199

(Edited by Zhu Xiuqin) 